\title{
Pay-per-download or Freemium: Revenue Models in a Competitive Mobile App Market
}

\author{
Xiaoxiao Luo \\ Tianjin University \\ luoxiaoxiao@tju.edu.cn
}

\author{
Jie Zhang \\ The University of Texas at Arlington \\ jiezhang@uta.edu
}

\author{
Minqiang Li \\ Tianjin University \\ mqli@tju.edu.cn
}

\begin{abstract}
This paper examines the revenue model selection of app developers in a duopoly setting. Two developers offering vertically-differentiated apps can adopt either a pay-per-download or a freemium strategy. Under the pay-per-download strategy, consumers pay a fee to acquire the app. Under the freemium strategy, consumers are offered with a free basic version and can choose to pay an additional fee for the full version. A game theoretical model is used to analyze the competition in the presence of network effect and learning effect. We find that when the quality difference is moderate, the pay-per-download strategy is optimal for the high-quality app if the quality of basic version is low, otherwise freemium strategy is optimal. Responding to the pay-per-download strategy of the high-quality app, adopting the pay-per-download strategy is optimal for the low-quality app if quality of basic version is high, otherwise freemium strategy is adopted.
\end{abstract}

\section{Introduction}

The comScore mobile report revealed that the number of mobile users surpassed desktop users in 2014. Gartner also predicted that over 268 billion smartphone application (“app”) downloads would generate an income of $\$ 77$ billion in 2017. The rising app downloads promise great potential for revenues. However the app market is extremely competitive and saturated. As of March 2017, there were 2.8 million available apps at Google Play Store and 2.2 billion apps available in the Apple's App Store, the two leading app stores in the world. This number is expected to increase in the future. Thus the market calls for careful and thorough analyses of the app developers' revenue models, especially in a competitive market.

According to software analyst firm VisionMobile, commonly app revenue models include freemium, in-app-purchase, pay-per-download, subscription and advertising. Among them, freemium and pay-per-download are among the top in terms of revenue generation for the developers. Under Pay-per-download, users pay a fee to acquire the apps, while under the freemium model, users are offered with a free trial version of apps before deciding whether to purchase the full version. Table 1 and Table 2 present a few examples of apps using the pay-per-download strategy and freemium strategy.

Table 1. Examples of Pay-per-download Apps

\begin{tabular}{|l|c|c|}
\hline App & Price & Category \\
\hline Monument Valley 2 & 4.99 & Games \\
\hline Enlight & 3.99 & Photo \& Video \\
\hline HotSchedules & 2.99 & Business \\
\hline Toca Hair Salon & 2.99 & Education \\
\hline Dark Sky Weather & 3.99 & Weather \\
\hline
\end{tabular}

Table 2. Examples of Freemium Apps

\begin{tabular}{|l|c|c|}
\hline App & Price & Category \\
\hline $\begin{array}{l}\text { Geometry Dash Lite } \\
\text { Geometry Dash }\end{array}$ & $\begin{array}{l}\text { Free } \\
1.99\end{array}$ & Games \\
\hline $\begin{array}{l}\text { Speak \& Translate - Voice and } \\
\text { Text Translator } \\
\text { Speak \& Translate - Live Voice } \\
\text { and Text Translator }\end{array}$ & Free & Reference \\
\hline $\begin{array}{l}\text { Live Wallpapers for Me - Free } \\
\text { Moving Backgrounds } \\
\text { Live Wallpapers for Me - } \\
\text { Animated HD Backgrounds }\end{array}$ & Free & $\begin{array}{c}\text { Entertainm } \\
\text { ent }\end{array}$ \\
\hline $\begin{array}{l}\text { Planes Live Free - Flight Status } \\
\text { Tracker \& Radar } \\
\text { Planes Live - Flight Status } \\
\text { Tracker \& Radar }\end{array}$ & Free & Travel \\
\hline $\begin{array}{l}\text { Scanner for Me - Free PDF } \\
\text { Scanner \& Printer App } \\
\text { Scanner for Me -PDF Scan with } \\
\text { OCR for Documents }\end{array}$ & Free & Business \\
\hline
\end{tabular}

Compared with the pay-per-download strategy, free trial under the freemium strategy affects app sales in several ways. First, offering two versions capture the network effect from both trial users and buyers. Due to a larger network, consumers have higher utilities, which may further increase consumer demand for the 
paid version and bring more profit to the app developer. Second, the demand for the paid version can be cannibalized by that for the free version because some consumers may find it sufficient to use the free version only and choose not to buy the full version. Third, after trying the basic version, consumers revise their beliefs about the full version. If the quality of the basic version is much higher than consumers' expectation, consumers raise their beliefs regarding the quality of the full version. For example, many game apps offer two versions to consumers, where the basic version provides some game stages for a free trial and the full version requires the users to pay to unlock the additional game stages. After trying the basic version, a user can tell whether she likes this kind of game or not. Due to the consistency in game design between the trial and full versions, the users can update the beliefs about the quality of the full version based on the experience of using the trials.

Considering network effect and experience-based learning effect, we study the competition between two app developers who offer vertically-differentiated apps. Specifically, we examine how consumers' expected quality and true quality of the two versions impact the developers' strategy choices between pay-per-download strategy and freemium strategy in equilibrium. This paper takes the initiative to analytically model and compare the most common revenue models for app developers, aiming to examine the equilibrium of how mobile developers choose revenue models in reaction to users' responses and competitors' strategies.

Our paper is related to the literature regarding free trial strategy of information products. The effect of free trial strategy was examined in empirical studies ([1], [8], [9]). Considering network effect, cannibalization effect and learning effect, the majority of extant studies ([2], [3], [4], [5], [6], [7], [11]) develop analytical model to examine limited version free trial, time-locked free trial, seeding strategies in a monopoly setting. Zhang et al. ([13]) studied freemium strategy in a duopoly setting, but they omitted the learning effect and derived conclusions by strictly assuming that the quality of the full version is identical among two firms. We consider network effect, cannibalization effect and learning effect to investigate the freemium strategy in a competition setting where the two app developers offer vertically-differentiated apps. Ma and Kauffman ([10]) investigated competition between software-as-a-service vendors by considering the sampling behavior of the clients. In their model, each client chooses one vendor for sampling and learns the exact value of the product after using it for a period of time. However, in the app market, the users are able to try all of the offered free versions before making the final decisions due to the negligible using cost, but they cannot get the exact value of the full version unless using it because of the difference of the functionality between the free version and the full version. The analysis based on our model provides insights for competition between app developers who consider adopting freemium strategy (offering limited-functionality version and full-functionality version) and pay-per-download strategy, where the learning effect, network effect and cannibalization effect are examined.

The rest of the paper is organized as follows. We introduce our general model framework in Section 2. The results are analyzed and discussed in Section 3. We finally conclude the paper in Section 4.

\section{Model}

We model competition between two app developers, who can adopt one of two strategies: (i) pay-per-download strategy, a strategy where consumers pay to get the app; (ii) freemium strategy, a strategy where the app developer offers the basic version for free and charges for the full version.

The sequence of the game is as follows. In stage 1, the app developers simultaneously decide their strategies to adopt. In stag 2, after observing the opponent's choice made in stage 1, the app developers announce the prices of their apps. In stage 3, consumers make purchase decisions based on their expected utilities. Specifically, when both app developers adopt the freemium strategy, each consumer tries both basic-version apps before making the final choice. Each consumer chooses to adopt an app from one of the developers, and decides the version if both versions are offered. Under the freemium strategy, before making the final purchase decision, consumers try the basic-version app and adjust their expected utilities toward the two versions according to the realized quality of the free version.

A consumer's expected utility is composed of two parts: the intrinsic valuation and the network-based valuation. The intrinsic valuation is determined by the quality preference of a consumer and the prior belief of the quality. $\theta_{i}$ measures consumer $i$ 's quality preference, which is uniformly distributed on the support of [0,1]. Let $a_{j}$ and $b_{j}(j=1,2)$ stand for the quality of the basic version and the full version of app $j$, respectively. We assume that consumers have consistent prior beliefs of the quality, and they do not know the true value of the quality until they purchase and experience the app. To capture uncertainty in the quality of the app prior to purchase, the quality of the basic version of app $j\left(a_{j}\right)$ is randomly drawn from a distribution with mean $a_{j 0}$ and variance $\sigma_{a_{j}}^{2}$, whereas 
the quality of full version of app $j\left(b_{j}\right)$ is randomly drawn from a distribution with mean $b_{j 0}$ and variance $\sigma_{b_{j}}^{2}$. After trying the basic functionalities of the free version, consumers under freemium strategy know the actual value of $a_{j}$ and adjust their belief of the full-version quality, which could be computed with

$$
\mathrm{E}\left(b_{j} \mid a_{j}\right)=b_{j 0}+\beta_{j}\left(a_{j}-a_{j 0}\right),
$$

where the intensity of learning effect $\beta_{j}=\rho_{j} \frac{\sigma_{b_{j}}}{\sigma_{a_{j}}}$ and $\rho_{j}$ describe the coefficient of correlation between $a_{j}$ and $b_{j}$. Therefore, consumeri's intrinsic valuation of app $j$ under pay-per-download strategy is $\theta_{i} b_{j 0}$. After trying the basic version under freemium strategy, consumer $i$ 's intrinsic valuation of the basic version of app $j$ is $\theta_{i} a_{j}$, and that of the full version is $\theta_{i} \mathrm{E}\left(b_{j} \mid a_{j}\right)$. Without loss of generality, we assume $b_{10}<b_{20} \quad$ and $\quad b_{10}+\beta_{1}\left(a_{1}-a_{10}\right)<b_{20}+$ $\beta_{2}\left(a_{2}-a_{20}\right)$.

Following Prasad et al. ([12]), we assume that the network-based valuations are linearly-increasing with the size of the user base and consumers have perfect foresight about equilibrium demand. Let $e_{j}$ denote the intensity of network effect of app $j$, which means the marginal utility that a consumer joins the network. Thus, the network-based valuation of app $j$ under pay-per-download strategy is $e_{j} d_{j}$, where $d_{j}$ stands for the demand of the app in equilibrium. The network-based valuation of app $j$ under freemium strategy is $e_{j}\left(d_{a_{j}}+d_{b_{j}}\right)$, where $d_{a_{j}}$ and $d_{b_{j}}$ represent the number of consumers paying nothing to use the basic version and the number of consumers purchasing the full version, respectively.

Let $p_{j}$ stand for the price of app $j$ under pay-per-download strategy or the price of the full version of app $j$ under freemium strategy. When app developer $j$ adopts pay-per-download strategy, the net utility of consumer $i$ toward app $j$ is

$$
u_{i j}^{P}=\theta_{i} b_{j 0}+e_{j} d_{j}-p_{j} .
$$

App developer $j$ sets the price $p_{j}$ to maximize his profit, which could be calculated by

$$
\Pi_{j}\left(p_{j}\right)=p_{j} d_{j} .
$$

When app developer $j$ adopts freemium strategy, after trying the basic version of the app, consumer $i$ 's utility toward the free version is

$$
u_{i j}^{F a}=\theta_{i} a_{j}+e_{j}\left(d_{a_{j}}+d_{b_{j}}\right),
$$

and her utility toward the full version is

$$
u_{i j}^{F b}=\theta_{i} \mathrm{E}\left(b_{j} \mid a_{j}\right)+e_{j}\left(d_{a_{j}}+d_{b_{j}}\right)-p_{j} .
$$

App developer $j$ sets the price $p_{j}$ to maximize his profit, which could be calculated by

$$
\Pi_{j}\left(p_{j}\right)=p_{j} d_{b_{j}} \text {. }
$$

\subsection{Case PP: Duopoly with Both App Developers Adopting Pay-Per-Download Strategy}

When two app developers both adopt pay-per-download strategy, each consumer chooses one of the two apps to maximize her utility. Thus, the market is divided into three segments, which is illustrated in Figure 1.

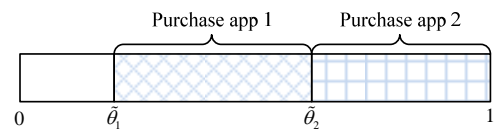

\section{Figure 1. Consumer segmentation when both app developers adopt pay-per-download strategy}

Consumers with low $\theta$ purchase nothing, and consumers with moderate $\theta$ purchase app 1 , and consumers with high $\theta$ purchase app 2. By setting $u_{i 1}^{P}=0$, we get the quality preference of the consumer who is indifferent regarding to purchase nothing or app 1

$$
\tilde{\theta}_{1}=\frac{p_{1}-e_{1} d_{1}}{b_{10}} .
$$

By setting $u_{i 1}^{P}=u_{i 2}^{P}$, we get the quality preference of the consumer who is indifferent regarding to purchase app 1 or app 2

$$
\tilde{\theta}_{2}=\frac{p_{2}-p_{1}+e_{1} d_{1}-e_{2} d_{2}}{b_{20}-b_{10}}
$$

Based on above expressions of indifferent points, we have the following equations

$$
\begin{aligned}
& d_{1}=\frac{b_{10}\left(p_{2}-e_{2} d_{2}\right)-b_{20}\left(p_{1}-e_{1} d_{1}\right)}{b_{10}\left(b_{20}-b_{10}\right)}, \\
& d_{2}=\frac{e_{2} d_{2}-e_{1} d_{1}+b_{20}-b_{10}-p_{2}+p_{1}}{b_{20}-b_{10}},
\end{aligned}
$$

and solve them to get the expressions of consumer demand. By substituting $d_{1}$ and $d_{2}$ into the profit function and solving the first order conditions of the profit functions, we find the equilibrium solutions of the sub-game Case PP.

Proposition 1. When $p_{1}-e_{1} d_{1}>0, d_{1}>0$, $b_{20}-b_{10}-p_{2}+p_{1}+e_{2} d_{2}-e_{1} d_{1}>0,2\left(e_{1}-b_{10}\right) /$ $\left(b_{10} b_{20}-b_{10}^{2}-e_{1} b_{20}-e_{2} b_{10}+e_{1} e_{2}\right)<0$

$2\left(e_{2}-b_{20}\right) /\left(b_{10} b_{20}-b_{10}^{2}-e_{1} b_{20}-e_{2} b_{10}+\right.$

$\left.e_{1} e_{2}\right)<0$, the prices in equilibrium are $p_{1}=$ $\left(b_{10}\left(b_{10} b_{20}-b_{10}^{2}-e_{1} b_{20}-2 e_{2} b_{10}+2 e_{1} e_{2}\right)\right) /$ $\left(4 b_{10} b_{20}-b_{10}^{2}-4 e_{2} b_{10}-4 e_{1} b_{20}+4 e_{1} e_{2}\right)$ $p_{2}=\left(2 b_{20}^{2} b_{10}-2 b_{10}^{2} b_{20}-2 e_{2} b_{10} b_{20}+e_{2} b_{10}^{2}-\right.$ $\left.2 e_{1} b_{20}^{2}+2 e_{1} e_{2} b_{20}\right) /\left(4 b_{10} b_{20}-b_{10}^{2}-4 e_{2} b_{10}-\right.$ $\left.4 e_{1} b_{20}+4 e_{1} e_{2}\right)$, the consumer demands in equilibrium are $d_{1}=\left(e_{2} p_{1}-e_{2} b_{10}+b_{10} p_{2}-\right.$ $\left.b_{20} p_{1}\right) /\left(b_{10} b_{20}-b_{10}^{2}-e_{1} b_{20}-e_{2} b_{10}+e_{1} e_{2}\right), d_{2}=$ $\left(b_{10} b_{20}-b_{10}^{2}-e_{1} b_{20}+e_{1} p_{2}-b_{10} p_{2}+b_{10} p_{1}\right) /$ $\left(b_{10} b_{20}-b_{10}^{2}-e_{1} b_{20}-e_{2} b_{10}+e_{1} e_{2}\right)$. 


\subsection{Case PF/FP: Duopoly with One App Developer Adopting Pay-Per-Download Strategy and One App Developer Adopting Freemium Strategy}

When app developer 1 adopts freemium strategy and app developer 2 adopts pay-per-download strategy, there are two cases of consumer segmentation, which are illustrated in Figure 2.

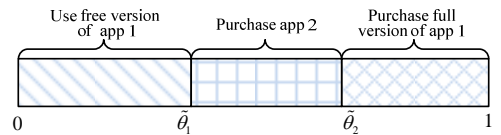

(a) Case 1: $\left\{\begin{array}{c}a_{1}<b_{20}<b_{10}+\beta_{1}\left(a_{1}-a_{10}\right) \\ 0<\tilde{\theta}_{1}<\tilde{\theta}_{2}<1\end{array}\right.$

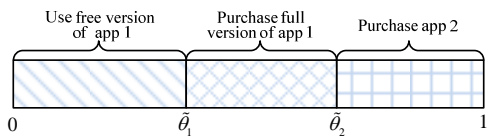

(b) Case 2: $\left\{\begin{array}{c}a_{1}<b_{10}+\beta_{1}\left(a_{1}-a_{10}\right)<b_{20} \\ 0<\tilde{\theta}_{1}<\tilde{\theta}_{2}<1\end{array}\right.$

Figure 2. Consumer segmentation when app developer 1 adopts freemium strategy and app developer 2 adopts pay-per-download strategy

In case 1 where $a_{1}<b_{20}<b_{10}+\beta_{1}\left(a_{1}-a_{10}\right)$, after trying the basic version of app 1 , consumers' expected quality of app 2 is lower than their expected quality of full version of app 1 . Consumers with low $\theta$ use basic version of app 1 for free, and consumers with moderate $\theta$ purchase app 2, and consumers with high $\theta$ purchase full version of app 1 . By setting $u_{i 1}^{F a}=u_{i 2}^{P}$ and $u_{i 2}^{P}=u_{i 1}^{F b}$, we get the expressions of the indifferent points as

$$
\begin{gathered}
\tilde{\theta}_{1}=\frac{p_{1}}{\beta_{1} a_{1}-\beta_{1} a_{10}-a_{1}+b_{10}} . \\
\tilde{\theta}_{2}=\frac{e_{2} d_{2}-e_{1} d_{a 1}-e_{1} d_{b 1}+p_{1}-p_{2}}{\beta_{1} a_{1}-\beta_{1} a_{10}+b_{10}-b_{20}} .
\end{gathered}
$$

In case 2 where $a_{1}<b_{10}+\beta_{1}\left(a_{1}-a_{10}\right)<b_{20}$, after trying the basic version of app 1 , consumers' expected quality of app 2 is higher than their expected quality of full version of app 1 . Thus, consumers with low $\theta$ use basic version of app 1 for free, and consumers with moderate $\theta$ purchase full version of app 1, and consumers with high $\theta$ purchase app 2. By setting $u_{i 1}^{I a}=u_{i 1}^{I b}$ and $u_{i 1}^{I b}=u_{i 2}^{P}$, the indifferent points could be computed by

$$
\begin{gathered}
\tilde{\theta}_{1}=\frac{e_{2} d_{2}-e_{1} d_{a 1}-e_{1} d_{b 1}-p_{2}}{a_{1}-b_{20}} . \\
\tilde{\theta}_{2}=\frac{e_{2} d_{2}-e_{1} d_{a 1}-e_{1} d_{b 1}+p_{1}-p_{2}}{\beta_{1} a_{1}-\beta_{1} a_{10}+b_{10}-b_{20}} .
\end{gathered}
$$

Based on the above expressions of indifferent points, we derive the expressions of consumer demand and further find the equilibrium solutions for the competition game when two app developers adopt different strategies. Due to the limitation of the space, we omit the specific expressions of prices, consumer demand and profit in equilibrium as well as corresponding conditions in subgame Case FP. When app developer 1 adopts pay-per-download strategy and app developer 2 adopts freemium strategy, the equilibrium of the subgame Case PF could be derived in a similar way.

\subsection{Case FF: Duopoly with Both App Developers Adopting Freemium Strategy}

When two app developers both adopt freemium strategy, consumers have four choices after trying basic versions of two apps. Four cases of consumer segmentation are illustrated in Figure 3.

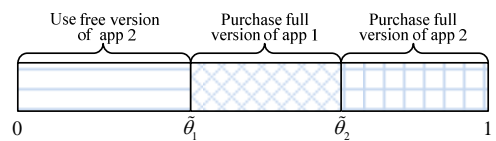

(a) Case 1:

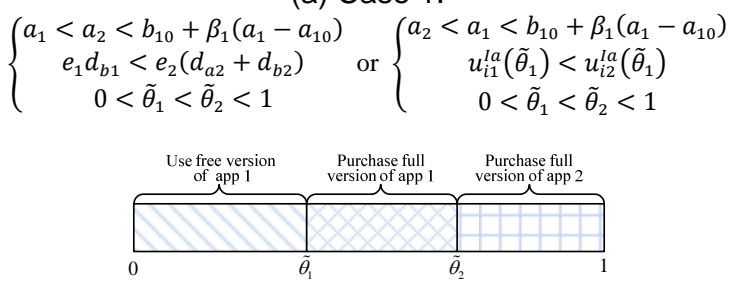

(b) Case 2:

$$
\begin{aligned}
& \left\{\begin{array} { c } 
{ a _ { 2 } < a _ { 1 } < b _ { 1 0 } + \beta _ { 1 } ( a _ { 1 } - a _ { 1 0 } ) } \\
{ e _ { 2 } d _ { b 2 } < e _ { 1 } ( d _ { a 1 } + d _ { b 1 } ) } \\
{ 0 < \tilde { \theta } _ { 1 } < \tilde { \theta } _ { 2 } < 1 }
\end{array} \text { or } \left\{\begin{array}{c}
a_{1}<a_{2}<b_{10}+\beta_{1}\left(a_{1}-a_{10}\right) \\
u_{i 2}^{I a}\left(\tilde{\theta}_{1}\right)<u_{i 1}^{I a}\left(\tilde{\theta}_{1}\right) \\
0<\tilde{\theta}_{1}<\tilde{\theta}_{2}<1
\end{array}\right.\right. \\
& \begin{array}{cccc}
\begin{array}{c}
\text { Use free } \\
\text { version } \\
\text { of app 1 }
\end{array} & \begin{array}{c}
\text { Use free } \\
\text { version } \\
\text { of app 2 }
\end{array} & \begin{array}{c}
\text { Purchase full } \\
\text { version of app 1 }
\end{array} & \begin{array}{c}
\text { Purchase full } \\
\text { version of app 2 }
\end{array} \\
\hline
\end{array}
\end{aligned}
$$

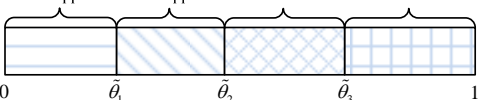

$$
\begin{aligned}
& \text { (c) Case 3: }\left\{\begin{array}{c}
a_{1}<a_{2}<b_{10}+\beta_{1}\left(a_{1}-a_{10}\right) \\
0<\tilde{\theta}_{1}<\tilde{\theta}_{2}<\tilde{\theta}_{3}<1
\end{array}\right.
\end{aligned}
$$

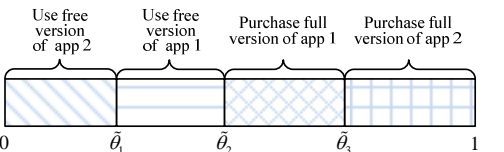

$$
\begin{aligned}
& \text { (d) Case 4: }\left\{\begin{array}{c}
a_{2}<a_{1}<b_{10}+\beta_{1}\left(a_{1}-a_{10}\right) \\
0<\tilde{\theta}_{1}<\tilde{\theta}_{2}<\tilde{\theta}_{3}<1
\end{array}\right.
\end{aligned}
$$

Figure 3. Consumer segmentation when both app developers adopt freemium strategy

In Case 1, no consumers only use basic version of app 1. Consumers with low $\theta$ use basic version of app 2 for free, and consumers with moderate $\theta$ purchase full version of app 1 , and consumers with high $\theta$ purchase full version of app 2. By setting $u_{i 2}^{F a}=u_{i 1}^{F b}$ and $u_{i 1}^{F b}=u_{i 2}^{F b}$, the indifferent points could be computed by 


$$
\begin{gathered}
\tilde{\theta}_{1}=\frac{e_{2} d_{a 2}+e_{2} d_{b 2}-e_{1} d_{b 1}+p_{1}}{\beta_{1} a_{1}-\beta_{1} a_{10}-a_{2}+b_{10}}, \\
\tilde{\theta}_{2}=\frac{e_{2} d_{a 2}+e_{2} d_{b 2}-e_{1} d_{b 1}+p_{1}-p_{2}}{\beta_{1} a_{1}-\beta_{2} a_{2}-\beta_{1} a_{10}+\beta_{2} a_{20}+b_{10}-b_{20}} .
\end{gathered}
$$

In Case 2, no consumers use basic version of app 2 only. Consumers with low $\theta$ use basic version of app 1 for free, and consumers with moderate-to-high $\theta$ purchase full versions of two apps. By setting $u_{i 1}^{F a}=u_{i 1}^{F b}$ and $u_{i 1}^{F b}=u_{i 2}^{F b}$, we get the indifferent points as

$$
\begin{gathered}
\tilde{\theta}_{1}=\frac{p_{1}}{\beta_{1} a_{1}-\beta_{1} a_{10}-a_{1}+b_{10}}, \\
\tilde{\theta}_{2}=\frac{e_{2} d_{b 2}-e_{1} d_{a 1}-e_{1} d_{b 1}+p_{1}-p_{2}}{\beta_{1} a_{1}-\beta_{2} a_{2}-\beta_{1} a_{10}+\beta_{2} a_{20}+b_{10}-b_{20}} .
\end{gathered}
$$

In Case 3 and Case 4 , consumers with low $\theta$ use basic versions of two apps, and consumers with high $\theta$ purchase full versions of two apps. The difference between these two cases is that the basic version of app 1 is favored by consumers with low $\theta$ in Case 3 but it's favored by consumers with moderate $\theta$ in Case 4. In Case 3 , setting $u_{i 1}^{F a}=u_{i 2}^{F a}, u_{i 2}^{F a}=u_{i 1}^{F b}$ and $u_{i 1}^{F b}=u_{i 2}^{F b}$, the expressions of the indifferent points are

$$
\begin{gathered}
\tilde{\theta}_{1}=\frac{e_{1} d_{a 1}-e_{2} d_{a 2}+e_{1} d_{b 1}-e_{2} d_{b 2}}{a_{2}-a_{1}}, \\
\tilde{\theta}_{2}=\frac{e_{1} d_{a 1}-e_{2} d_{a 2}+e_{1} d_{b 1}-e_{2} d_{b 2}-p_{1}}{\beta_{1} a_{10}-\beta_{1} a_{1}+a_{2}-b_{10}}, \\
\tilde{\theta}_{3}=\frac{e_{1} d_{a 1}-e_{2} d_{a 2}+e_{1} d_{b 1}-e_{2} d_{b 2}-p_{1}+p_{2}}{\beta_{1} a_{10}-\beta_{2} a_{20}-\beta_{1} a_{1}+\beta_{2} a_{2}-b_{10}+b_{20}} .
\end{gathered}
$$

In Case 4 , the expressions of $\tilde{\theta}_{1}$ and $\tilde{\theta}_{3}$ could be computed with Equation (19) and Equation (21) . By setting $u_{i 1}^{F a}=u_{i 1}^{F b}$, the expressions of $\tilde{\theta}_{2}$ is

$$
\tilde{\theta}_{2}=\frac{p_{1}}{\beta_{1} a_{1}-\beta_{1} a_{10}-a_{1}+b_{10}} \text {. }
$$

Based on the above expressions of indifferent points, we can compute consumer demand and further find the equilibrium solutions. Due to the limitation of the space, we omit the specific expressions of prices, consumer demand and profit in equilibrium as well as corresponding conditions in subgame Case FF.

\section{Analysis}

Because the sub-game-perfect Nash equilibrium of the four cases derived in Section 2 is complicated, we resort to numerical methods to solve the $2 \times 2$ payoff matrix to get the market equilibrium of the game. By setting $a_{10}=0.2, a_{20}=0.3, e_{1}=0.01, e_{2}=$ $0.02, \beta_{1}=0.3$ and $\beta_{2}=0.3$, we analyze the four equilibriums and explain how the quality of basic versions $a_{1}$ and $a_{2}$ impact market equilibrium solutions when the difference in consumers' expected quality toward full versions of two apps is moderate ( $b_{10}=0.8$ and $b_{20}=1$ ) in section 3.1-3.5, and we further analyze the impact of $b_{10}$ and $b_{20}$ on market equilibrium solutions in section 3.6. In section 3.7 and 3.8, we examine how $e_{1}, e_{2}, \beta_{1}$ and $\beta_{2}$ affect profits of two app developers in four cases.

\subsection{Equilibrium PP}

Table 3 and Table 4 present equilibrium profits, prices and consumer demand for the four possible market configurations when $a_{1}$ is large but $a_{2}$ is small $\left(a_{1}=0.3\right.$ and $\left.a_{2}=0.1\right)$.

Table 3. The equilibrium profits for the four possible market configurations

\begin{tabular}{|c|c|c|}
\hline App 1 & $\begin{array}{c}\text { App-per-download } \\
\text { strategy }\end{array}$ & $\begin{array}{c}\text { Freemium } \\
\text { strategy }\end{array}$ \\
\hline $\begin{array}{c}\text { Pay-per-download } \\
\text { strategy }\end{array}$ & $\Pi_{1}^{P P}=0.011$ & $\Pi_{1}^{P F}=0.005$ \\
$\Pi_{2}^{P P}=0.077$ & $\Pi_{2}^{P F}=0.053$ \\
\hline Freemium & $\Pi_{1}^{F P}=0.008$ & $\Pi_{1}^{F F}=0.004$ \\
strategy & $\Pi_{2}^{F P}=0.064$ & $\Pi_{2}^{F F}=0.042$ \\
\hline
\end{tabular}

Table 4. The equilibrium prices and demand under the four possible market configurations

\begin{tabular}{|c|c|c|}
\hline & Price & Demand \\
\hline \multirow{2}{*}{ Case PP } & $p_{1}^{P P}=0.039$ & $d_{1}^{P P}=0.282$ \\
& $p_{2}^{P P}=0.114$ & $d_{2}^{P P}=0.674$ \\
\hline \multirow{2}{*}{ Case FP } & $p_{1}^{F P}=0.030$ & $d_{a 1}^{F P}=0.056, d_{b 1}^{F P}=0.267$ \\
& $p_{2}^{F P}=0.095$ & $d_{2}^{F P}=0.677$ \\
\hline \multirow{2}{*}{ Case PF } & $p_{1}^{P F}=0.022$ & $d_{1}^{P F}=0.251$ \\
& $p_{2}^{P F}=0.076$ & $d_{a 2}^{P F}=0.049, d_{b 2}^{P F}=0.701$ \\
\hline \multirow{2}{*}{ Case FF } & $p_{1}^{F F}=0.015$ & $d_{a 1}^{F F}=0, d_{b 1}^{F F}=0.235$ \\
& $p_{2}^{F F}=0.058$ & $d_{a 2}^{F F}=0.039, d_{b 2}^{F F}=0.726$ \\
\hline
\end{tabular}

Because $a_{2}<a_{20}$, consumers' expected quality of full version after trying the basic version is lower than that before trying the basic version. Thus, app developer 2 chooses pay-per-download strategy to avoid the decreases of consumers' expected quality. In that way, app developer 2 can charge a much higher price. Although the consumer demand under pay-per-download strategy is slightly lower than that under freemium strategy, the app developer 2 can earn more profit under pay-per-download strategy.

Because $a_{1}>a_{10}$, consumers' expected quality of full version increases after trying the basic version, which shrinks the difference in the quality of two apps and intensify competition. In order to moderate the competition, app developer 1 adopts pay-per-download strategy. Compared with adopting freemium strategy, when app developer 1 adopts pay-per-download strategy, he can charge a higher price and get more consumers to purchase the full version.

Case PP is an equilibrium when $a_{1}$ is large but $a_{2}$ is small. In equilibrium, consumers with moderate quality preference buy app 1 and consumers with high quality preference buy app 2 . 


\subsection{Equilibrium FP}

In Table 5 and Table 6, we present equilibrium results for the four possible market configurations when $a_{1}$ and $a_{2}$ are small $\left(a_{1}=0.1\right.$ and $\left.a_{2}=0.2\right)$.

Table 5. The equilibrium profits for the four possible market configurations

\begin{tabular}{|c|c|c|}
\hline App 1 & $\begin{array}{c}\text { Pay-per-download } \\
\text { strategy }\end{array}$ & $\begin{array}{c}\text { Freemium } \\
\text { strategy }\end{array}$ \\
\hline $\begin{array}{c}\text { Pay-per-download } \\
\text { strategy }\end{array}$ & $\begin{array}{l}\Pi_{1}^{P P}=0.011 \\
\Pi_{2}^{P P}=0.077\end{array}$ & $\begin{array}{l}\Pi_{1}^{P F}=0.007 \\
\Pi_{2}^{P F}=0.063\end{array}$ \\
\hline $\begin{array}{c}\text { Freemium } \\
\text { strategy }\end{array}$ & $\begin{array}{l}\Pi_{1}^{F P}=0.012 \\
\Pi_{2}^{F P}=0.086\end{array}$ & $\begin{array}{l}\Pi_{1}^{F F}=0.008 \\
\Pi_{2}^{F F}=0.073\end{array}$ \\
\hline
\end{tabular}

Table 6. The equilibrium prices and demand under the four possible market configurations

\begin{tabular}{|c|c|c|}
\hline & Price & Demand \\
\hline \multirow{2}{*}{ Case PP } & $p_{1}^{P P}=0.039$ & $d_{1}^{P P}=0.282$ \\
& $p_{2}^{P P}=0.114$ & $d_{2}^{P P}=0.674$ \\
\hline \multirow{2}{*}{ Case FP } & $p_{1}^{F P}=0.043$ & $d_{a 1}^{F P}=0.064, d_{b 1}^{F P}=0.279$ \\
& $p_{2}^{F P}=0.131$ & $d_{2}^{F P}=0.657$ \\
\hline \multirow{2}{*}{ Case PF } & $p_{1}^{P F}=0.027$ & $d_{1}^{P F}=0.259$ \\
& $p_{2}^{P F}=0.094$ & $d_{a 2}^{P F}=0.065, d_{b 2}^{P F}=0.677$ \\
\hline \multirow{2}{*}{ Case FF } & $p_{1}^{F F}=0.030$ & $d_{a 1}^{F F}=0, d_{b 1}^{F F}=0.256$ \\
& $p_{2}^{F F}=0.109$ & $d_{a 2}^{F F}=0.075, d_{b 2}^{F F}=0.67$ \\
\hline
\end{tabular}

After trying the basic version of app 2 whose true value of the quality is lower than consumers' prior belief $\left(a_{2}<a_{20}\right)$, users decrease their expected quality toward the full version of app 2. Although the app developer loses some consumers when he turns from freemium strategy to pay-per-download strategy, he can charge a higher price and earn more profit. Thus, app developer 2 adopts pay-per-download strategy.

Because $a_{1}<a_{10}$, consumers decrease their expected quality of the full version of app 1 after trying the basic version. Consequently, consumers' expected quality of the full version of app 1 under pay-per-download strategy is higher than the adjusted expected quality under freemium strategy. To moderate competition with app 2, app developer 1 adopts freemium strategy to lower consumers' expected quality of his app. Compared with adopting pay-per-download strategy, app developer 1 adopting freemium strategy can charge a significantly higher price at the cost of losing few consumers, which brings more profit to the developers.

Case FP is an equilibrium when $a_{1}$ and $a_{2}$ are small. In equilibrium, consumers with low quality preference use basic version of app 1, and those with moderate quality preference buy full version of app 1, and those with high quality preference buy app 2 .

\subsection{Equilibrium PF}

Table 7 and Table 8 present equilibrium results for the four possible market configurations when $a_{1}$ is small and $a_{2}$ is large $\left(a_{1}=0.1\right.$ and $\left.a_{2}=0.6\right)$.

Table 7. The equilibrium profits for the four possible market configurations

\begin{tabular}{|c|c|c|}
\hline App 11 App 2 & $\begin{array}{c}\text { Pay-per-download } \\
\text { strategy }\end{array}$ & $\begin{array}{l}\text { Freemium } \\
\text { strategy }\end{array}$ \\
\hline $\begin{array}{l}\text { Pay-per-download } \\
\text { strategy }\end{array}$ & $\begin{array}{l}\Pi_{1}^{P P}=0.011 \\
\Pi_{2}^{P P}=0.077\end{array}$ & $\begin{array}{l}\Pi_{1}^{P F}=0.005 \\
\Pi_{2}^{P F}=0.090\end{array}$ \\
\hline $\begin{array}{l}\text { Freemium } \\
\text { strategy }\end{array}$ & $\begin{array}{l}\Pi_{1}^{F P}=0.012 \\
\Pi_{2}^{F P}=0.086\end{array}$ & $\begin{array}{l}\Pi_{1}^{F F}=0.004 \\
\Pi_{2}^{F F}=0.096\end{array}$ \\
\hline
\end{tabular}

Table 8. The equilibrium prices and demand under the four possible market configurations

\begin{tabular}{|c|c|c|}
\hline & Price & Demand \\
\hline \multirow{2}{*}{ Case PP } & $p_{1}^{P P}=0.039$ & $d_{1}^{P P}=0.282$ \\
& $p_{2}^{P P}=0.114$ & $d_{2}^{P P}=0.674$ \\
\hline \multirow{2}{*}{ Case FP } & $p_{1}^{F P}=0.043$ & $d_{a 1}^{F P}=0.064, d_{b 1}^{F P}=0.279$ \\
& $p_{2}^{F P}=0.131$ & $d_{2}^{F P}=0.657$ \\
\hline \multirow{2}{*}{ Case PF } & $p_{1}^{P F}=0.021$ & $d_{1}^{P F}=0.237$ \\
& $p_{2}^{P F}=0.151$ & $d_{a 2}^{P F}=0.169, d_{b 2}^{P F}=0.594$ \\
\hline \multirow{2}{*}{ Case FF } & $p_{1}^{F F}=0.019$ & $d_{a 1}^{F F}=0, d_{b 1}^{F F}=0.230$ \\
& $p_{2}^{F F}=0.165$ & $d_{a 2}^{F F}=0.187, d_{b 2}^{F F}=0.584$ \\
\hline
\end{tabular}

When the true value of quality for the basic version of app 2 is higher than consumers' expected quality $\left(a_{2}>a_{20}\right)$, consumers increase their expected quality toward full version of app 2 after trying the basic version. Thus, app developer 2 can use freemium strategy to charge a higher price and earn a larger amount of revenue.

As analyzed in section 3.2, when $a_{1}<a_{10}$, consumers' expected quality toward full version of app 1 decreases after trying the basic version. To moderate competition between high-quality free version of app 2 and paid version of app 1, app developer 1 has to adopt pay-per-download strategy rather than freemium strategy to keep consumers' expected quality toward full version as higher as possible. Under pay-per-download strategy, the app developer 1 can charge a higher price and also get more consumer demand.

Case PF is an equilibrium when $a_{1}$ is small and $a_{2}$ is large. In equilibrium, consumers with low quality preference use basic version of app 2 for free, and consumers with moderate preference choose app 1, and consumers with high preference purchase full version of app 2. 


\subsection{Equilibrium FF}

Table 9 and Table 10 present equilibrium results for the four possible market configurations when $a_{1}$ and $a_{2}$ are large $\left(a_{1}=0.3\right.$ and $\left.a_{2}=0.7\right)$.

Table 9. The equilibrium profits for the four possible market configurations

\begin{tabular}{|c|c|c|}
\hline App 1 & $\begin{array}{c}\text { Pay-per-download } \\
\text { strategy }\end{array}$ & $\begin{array}{l}\text { Freemium } \\
\text { strategy }\end{array}$ \\
\hline $\begin{array}{l}\text { Pay-per-download } \\
\text { strategy }\end{array}$ & $\begin{array}{l}\Pi_{1}^{P P}=0.011 \\
\Pi_{2}^{P P}=0.077\end{array}$ & $\begin{array}{l}\Pi_{1}^{P F}=0.002 \\
\Pi_{2}^{P F}=0.092\end{array}$ \\
\hline $\begin{array}{l}\text { Freemium } \\
\text { strategy }\end{array}$ & $\begin{array}{l}\Pi_{1}^{F P}=0.008 \\
\Pi_{2}^{F P}=0.064\end{array}$ & $\begin{array}{l}\Pi_{1}^{F F}=0.003 \\
\Pi_{2}^{F F}=0.086\end{array}$ \\
\hline
\end{tabular}

Table 10. The equilibrium prices and demand under the four possible market configurations

\begin{tabular}{|c|c|c|}
\hline & Price & Demand \\
\hline \multirow{2}{*}{ Case PP } & $p_{1}^{P P}=0.039$ & $d_{1}^{P P}=0.282$ \\
& $p_{2}^{P P}=0.114$ & $d_{2}^{P P}=0.674$ \\
\hline \multirow{2}{*}{ Case FP } & $p_{1}^{F P}=0.030$ & $d_{a 1}^{F P}=0.056, d_{b 1}^{F P}=0.267$ \\
& $p_{2}^{F P}=0.095$ & $d_{2}^{F P}=0.677$ \\
\hline \multirow{2}{*}{ Case PF } & $p_{1}^{P F}=0.009$ & $d_{1}^{P F}=0.194$ \\
& $p_{2}^{P F}=0.159$ & $d_{a 2}^{P F}=0.231, d_{b 2}^{P F}=0.575$ \\
\hline \multirow{2}{*}{ Case FF } & $p_{1}^{F F}=0.013$ & $d_{a 1}^{F F}=0, d_{b 1}^{F F}=0.211$ \\
& $p_{2}^{F F}=0.146$ & $d_{a 2}^{F F}=0.202, d_{b 2}^{F F}=0.586$ \\
\hline
\end{tabular}

Due to $a_{2}>a_{20}$, the app developer 2 adopts freemium strategy. Because consumers increase their expected quality toward full version of app 2 after trying the basic version, the app developer 2 can charge a higher price and earn more profit under freemium strategy.

Because app developer 2 offers a free version of high quality, app developer 1 has to face an intensive competition from free version of app 2. To increase consumers' expected quality of full version of app 1, app developer 1 adopts freemium strategy. In that way, app developer 1 can charge a higher price and also get more consumers.

Case $\mathrm{FF}$ is an equilibrium when $a_{1}$ and $a_{2}$ are large. In equilibrium, no consumers use free version of app 1. Consumers with low quality preference choose free version of app 2, and consumers with moderate quality preference buy full version of app 1, and consumers with high quality preference purchase full version of app 2.

\subsection{Impact of $a_{1}$ and $a_{2}$ on Market equilibrium}

Figure 4 illustrates how quality of the basic versions $a_{1}$ and $a_{2}$ impact the strategy adopted by each app developer in equilibrium. We further summarize our observations in Results 1 .

Results 1. If $b_{20}>b_{10}$ and the difference of $b_{10}$ and $b_{20}$ is moderate, market equilibria under different $\left(a_{1}, a_{2}\right)$ are:

i) Case FP is an equilibrium when $a_{1}$ is small and $a_{2}$ is small;

ii) Case PF is an equilibrium when $a_{1}$ is small and $a_{2}$ is large or when $a_{1}$ is large and $a_{2}$ is moderate;

iii) Case PP is an equilibrium when $a_{1}$ is large and $a_{2}$ is small;

iv) Case FF is an equilibrium when $a_{1}$ is small and $a_{2}$ is moderate or when $a_{1}$ is large and $a_{2}$ is large.

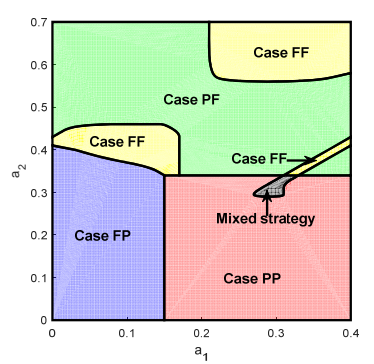

Figure 4. Market equilibria in $a_{1}-a_{2}$ space

Notes. Figure 4 is based on $a_{10}=0.2, a_{20}=0.3, b_{10}=0.8$, $b_{20}=1, e_{1}=0.01, e_{2}=0.02, \beta_{1}=0.3$ and $\beta_{2}=0.3$.

App developer 2, who offers high-quality app, adopts pay-per-download strategy when $a_{2}$ is small, but he adopts freemium strategy when $a_{2}$ is large. If the true value of the quality $a_{2}$ is much higher than consumer's expected quality $a_{20}$, the app developer prefers to offer a basic version because consumers' expected quality of the full version increases after they try the basic version. If $a_{2}$ is lower than $a_{20}$, the app developer has no incentive to offer a basic version. Trying the basic version decreases consumers' expected quality of the full version and reduces the profit of the app developer. If $a_{2}$ is slightly higher than $a_{20}$, the app developer adopts pay-per-download strategy. Although offering the basic version can slightly increase consumers' expected quality of the full version, it cannibalizes demand of the full version, which hurts the developer's profit.

When $a_{1}$ is small, where consumers decrease their expected quality of the full version after trying the basic version, we find that app developer 1 chooses freemium strategy when $a_{2}$ is small-to-moderate. When $a_{1}$ is large, consumers' expected quality of the full version increases after trying the basic version. However, app developer 1 adopts pay-per-download strategy rather than freemium strategy when $a_{2}$ is small-to-moderate. The rationale behind these 
counter-intuitive results is that the strategy adopted by app developer 1 helps to lower consumers' expected quality of the full version and enlarge the difference in the quality of two apps, which reduces competition between two app developers and enable them to earn more profit.

When $a_{2}$ is large, where app developer 2 adopts freemium strategy, app developer 1 will choose the strategy that can increase consumers' expected quality of the full version to moderate competition against the free version of app 2. Therefore, app developer 1 adopts pay-per-download strategy to avoid decrease of expected quality after trying the basic version when $a_{1}$ is small, and he adopts freemium strategy to increase consumers' expected quality by offering free version when $a_{1}$ is large.

\subsection{Impact of $b_{10}$ and $b_{20}$ on Market equilibrium}

Figure 5 illustrate how consumers' expected quality of the full versions $b_{10}$ and $b_{20}$ impact the equilibrium. We further summarize our observations in Results 2.

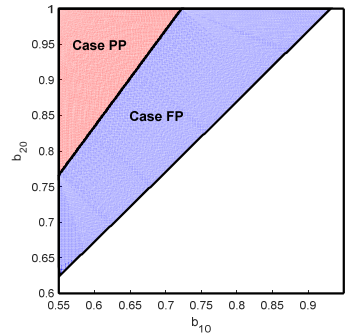

(a) $a_{1}=0.1, a_{2}=0.25$

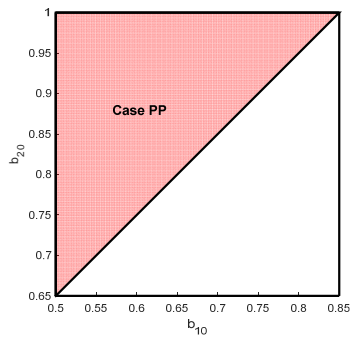

(c) $a_{1}=0.4, a_{2}=0.2$

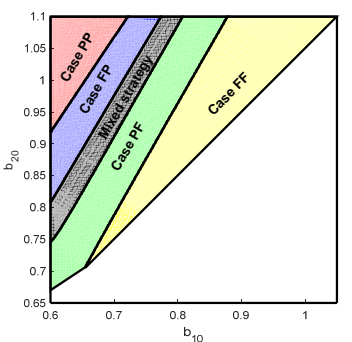

(b) $a_{1}=0.05, a_{2}=0.5$

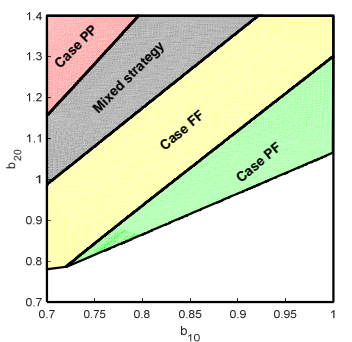

(d) $a_{1}=0.25, a_{2}=0.6$

Figure 5. Market equilibria in $b_{10}-b_{20}$ space

Notes. Figure 5 is based on $a_{10}=0.2, a_{20}=0.3, e_{1}=0.01$, $e_{2}=0.02, \beta_{1}=0.3$ and $\beta_{2}=0.3$.

Results 2. When $b_{20}>b_{10}$, as the difference of $b_{10}$ and $b_{20}$ increases, the changes of market equilibria are:

i) If $a_{1}$ and $a_{2}$ are small, the equilibrium changes from Case FP to Case PP;

ii) If $a_{1}$ is small and $a_{2}$ is large, the equilibrium changes from Case FF, Case PF to Case FP and Case
$P P$

iii) If $a_{1}$ is large and $a_{2}$ is small, the equilibrium is Case PP;

iv) If $a_{1}$ and $a_{2}$ are large, the equilibrium changes from Case PF, Case FF to Case PP.

When the true values of quality of basic versions are lower than consumers' prior belief, app developer 2 adopts pay-per-download strategy to avoid the decrease of consumers' expected quality toward the full version. The response of app developer 1 depends on the difference of $b_{10}$ and $b_{20}$. When $b_{10}$ is close to $b_{20}$, app developer 1 uses freemium strategy to decrease consumers' expected quality of the full version by offering the basic version for trial. In that way, the difference of consumers' expected quality of two apps enlarges, which moderate the competition. When $b_{10}$ is much lower than $b_{20}$, the competition between the two apps is weak. Therefore, app developer 1 uses pay-per-download strategy to increase consumers' expected quality and earn more profit.

When $a_{1}$ is lower than $a_{10}$ and $a_{2}$ is higher than $a_{20}$, app developer 2 adopts freemium strategy when $b_{10}$ is close to $b_{20}$ but he uses pay-per-download strategy when $b_{10}$ is much lower than $b_{20}$. In the former situations, faced with intensive competition, app developer 2 offers basic version to increase consumers' expected quality of full version and get more consumers. In the latter situations, the competition between two apps is weak. App developer 2 prefers to use pay-per-download strategy rather than freemium strategy to avoid cannibalization effect of the free version. As for the response of app developer 1, he uses freemium strategy to increase quality difference of two apps when $b_{10}$ is higher, and he adopts pay-per-download strategy to charge a higher price when $b_{10}$ is lower.

When $a_{1}$ is higher than $a_{10}$ and $a_{2}$ is lower than $a_{20}$, both app developers adopt pay-per-download strategy in equilibrium. Because $a_{2}<a_{20}$, app developer 2 has no incentive to offer the free version. Although $a_{1}>a_{10}$, to avoid causing intense competition against app 2 and cannibalizing demand of full version, app developer 1 doesn't offer free version in equilibrium. That is, the best response of app developer 1 is to use pay-per-download strategy.

When $a_{1}$ and $a_{2}$ are higher compared with $a_{10}$ and $a_{20}$, app developer 2 adopts freemium strategy to increase consumers' expected quality toward full version if $b_{20}$ is close to $b_{10}$ where the competition is intense, while he uses pay-per-download strategy to avoid free version cannibalizing demand of full version if $b_{20}$ is much higher than $b_{10}$ where the competition is weak. Responding to pay-per-download strategy adopted by app developer 2, app developer 1 uses pay-per-download strategy which helps to moderate 
competition and avoids cannibalizing effect of the free version. Responding to freemium strategy adopted by app developer 2, app developer 1 uses pay-per-download strategy when the difference of $b_{10}$ and $b_{20}$ is small, whereas he adopts freemium strategy when the difference of $b_{10}$ and $b_{20}$ is moderate. The rationale is as follows. Compared with adopting pay-per-download strategy, using freemium strategy increases consumers' expected quality of the full version but shrinks the difference in expected quality of two apps. Therefore, freemium strategy will be used by app developer 1 only if the difference of $b_{10}$ and $b_{20}$ is not low.

\subsection{Impact of $e_{1}$ and $e_{2}$ on Profits}

Figure 6 illustrates how the intensity of network effects $e_{1}$ and $e_{2}$ impacts the profits of app developers in four cases. Our observations are summarized in Results 3.
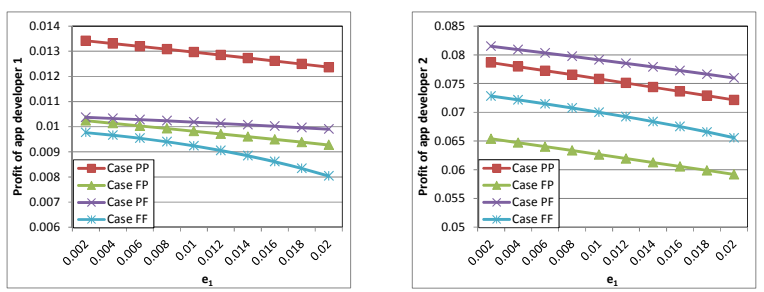

(a) The change of profits with respect to $e_{1}$
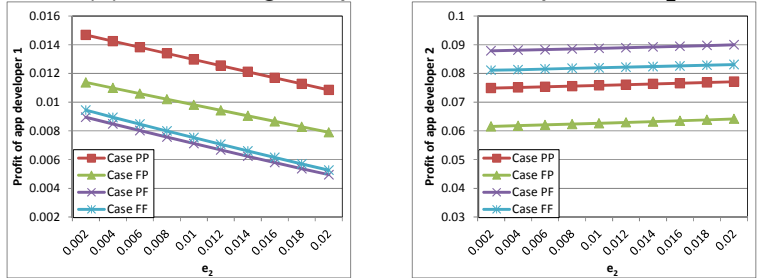

(b) The change of profits with respect to $e_{2}$

Figure 6. The change of profits with respect to intensity of network effects

Note: Figures are based on $a_{1}=0.3, a_{2}=0.4, a_{10}=0.2$, $a_{20}=0.3, b_{10}=0.8, b_{20}=1, \beta_{1}=0.3$ and $\beta_{2}=0.3$. $e_{2}=0.01$ for Figure 6(a) and $e_{1}=0.01$ for Figure 6(b).

Results 3. The impact of network effect on profits of app developers is as follows:

i) as the intensity of network effect of app 1 increases, the profits of two app developers decrease;

ii) as the intensity of network effect of app 2 increases, the profit of app 1 decreases but the profit of app 2 increases.

With the increase of the intensity of network effect of app 1, consumers' valuation toward app 1 increases, which reduces the differentiation of two apps and intensifies the competition, thus both app developers lose profit. With the increase of the intensity of network effect of app 2, consumer's valuation toward app 2 increases. The app developer 2 charges a lower price to attract a larger number of users, thus he earns more profit. Faced with the lower price charged by the competitor, the app developer 1 has to reduce his price but lose some users, thus his profit decreases.

\subsection{Impact of $\beta_{1}$ and $\beta_{2}$ on Profits}

Figure 7 illustrates how the intensity of learning effect $\beta_{1}$ and $\beta_{2}$ impacts the profits of app developers in four cases. Our observations are summarized in Results 4.
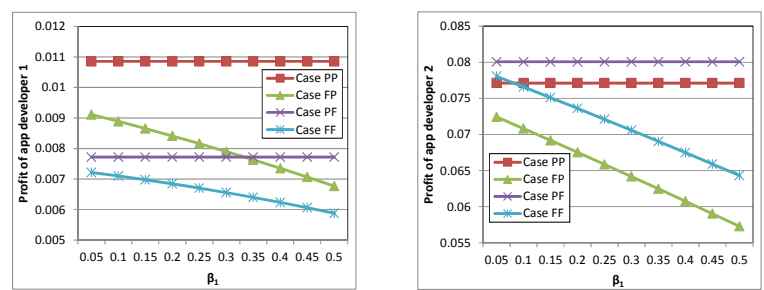

(a) The change of profits with respect to $\beta_{1}$
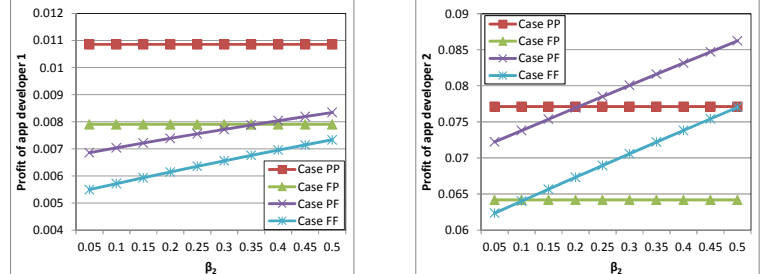

(b) The change of profits with respect to $\beta_{2}$

Figure 7. The change of profits with respect to intensity of learning effects

Note: Figures are based on $a_{1}=0.3, a_{2}=0.4, a_{10}=0.2$, $a_{20}=0.3, b_{10}=0.8, b_{20}=1, e_{1}=0.01$ and $\beta_{2}=0.02$. $\beta_{2}=0.3$ for Figure 7(a) and $\beta_{1}=0.3$ for Figure 7(b).

Results 4. When consumers' beliefs increase after free trials, the impact of learning effect on profits of app developers is as follows:

i) as the intensity of learning effect of app 1 increases, the profits of two app developers decrease;

ii) as the intensity of learning effect of app 2 increases, the profits of two app developers increase.

In situations where consumers' quality beliefs increase after free trials, as the intensity of learning effect of app 1 increases, consumers generate higher valuations toward the full version of app 1 when the free version is offered. The differentiation of apps created by two developers reduces, thus the two app developers decrease app prices, which hurt their profits. As the intensity of learning effect of app 2 increases, consumers generate higher valuations toward full version of app 2 when free version is offered. Thus, the differentiation of apps created by the two app developers increases, which enables the two app 
developers to charge higher prices and earn more profits.

\section{Conclusion}

Motivated by practical examples in app market, we analyze how app developers choose revenue model in a duopoly setting. The two app developers offer vertically-differentiated apps and choose to adopt pay-per-download strategy or freemium strategy in the presence of network effect and experience-based learning effect.

We find that when the difference in consumers' expected quality of full versions of two apps is large, both app developers use pay-per-download strategy, otherwise each app developer may adopt either one of the strategies depending on specific conditions. When the difference in consumers' expected quality of full versions of two apps is moderate, the developer offering high-quality app uses freemium strategy if true quality of the free version is much higher than consumers' belief, otherwise he chooses pay-per-download strategy. However, the response of developer offering low-quality app can be totally conversed according to the relationship of consumer belief and true quality. When the competitor offering high-quality app uses pay-per-download strategy, the developer offering low-quality app chooses pay-per-download strategy if true quality of the free version is much higher than consumers' belief, otherwise he chooses freemium strategy.

Our findings show that the app developers in the market with intensive competition should adopt the strategy that can raise the differentiation between the products and reduce the competition. For example, if the consumers' beliefs of two apps decrease after free trial, the app developer should adopt pay-per-download strategy when the users prefer his app but freemium strategy when the users prefer the app created by the competitor. The leader in the market only offers a full version to avoid the decrease of consumers' belief after free trial. Responding to the action of the leader, the follower in the market augments the differentiation of the two apps and earns more profit by offering the free version to decrease consumers' belief of his own app. In addition to the competition effect, the app developer should also consider the cannibalization effect. In situations where consumers' beliefs of the apps increase after free trial, the leader can use pay-per-download strategy to maximize his profit when the difference in consumers' beliefs of two apps is significant. Because of the weak competition, the developer mainly considers cannibalization effect and chooses to offer only the full version to avoid cannibalization of demands of two versions.
Our analysis can be further extended in multiple ways. First, we assume that the quality of free version is exogenous, but the decision of quality can be considered to provide more guidelines on app design. Second, other than pay-per-download strategy and freemium strategy, in-app-purchase strategy and subscription strategy are also prevalent in app market, which are worth investigating in competition environment.

\section{Reference}

[1] Chen, H., Duan, W.J., and Zhou, W.Q. The interplay between free sampling and word of mouth in the online software market. Decision Support Systems, 95 (2017), 82-90.

[2] Cheng, H.K., Li, S., and Liu, Y. Optimal Software Free Trial Strategy: Limited Version, Time-locked, or Hybrid? Production and Operations Management, 24, 3 (2015), 504-517.

[3] Cheng, H.K., and Liu, Y.P. Optimal Software Free Trial Strategy: The Impact of Network Externalities and Consumer Uncertainty. Information Systems Research, 23, 2 (2012), 488-504.

[4] Cheng, H.K., and Tang, Q.C. Free trial or no free trial: Optimal software product design with network effects. European Journal of Operational Research, 205, 2 (2010), 437-447.

[5] Dey, D., Lahiri, A., and Liu, D.P. Consumer Learning and Time-Locked Trials of Software Products. Journal of Management Information Systems, 30, 2 (2013), 239-267.

[6] Dou, Y.F., Niculescu, M.F., and Wu, D.J. Engineering Optimal Network Effects via Social Media Features and Seeding in Markets for Digital Goods and Services. Information Systems Research, 24, 1 (2013), 164-185.

[7] Jiang, Z.R., and Sarkar, S. Speed Matters: The Role of Free Software Offer in Software Diffusion. Journal of Management Information Systems, 26, 3 (2009), 207-239.

[8] Lee, Y.J., and Tan, Y. Effects of Different Types of Free Trials and Ratings in Sampling of Consumer Software: An Empirical Study. Journal of Management Information Systems, 30, 3 (2013), 213-246.

[9] Liu, C.Z.C., Au, Y.A., and Choi, H.S. Effects of Freemium Strategy in the Mobile App Market: An Empirical Study of Google Play. Journal of Management Information Systems, 31, 3 (2014), 326-354.

[10] Ma, D., and Kauffman, R.J. Competition Between Software-as-a-Service Vendors. IEEE Transactions on Engineering Management, 61, 4 (2014), 717-729.

[11] Niculescu, M.F., and Wu, D.J. Economics of Free Under Perpetual Licensing: Implications for the Software Industry. Information Systems Research, 25, 1 (2014), 173-199.

[12] Prasad, A., Venkatesh, R., and Mahajan, V. Optimal Bundling of Technological Products with Network Externality. Management Science, 56, 12 (2010), 2224-2236. [13] Zhang, Z., Nan, G., Li, M., and Tan, Y. Duopoly Pricing Strategy for Information Products with Premium Service: Free Product or Bundling? Journal of Management Information Systems, 33, 1 (2016), 260-295. 